\title{
TOWARDS AN OPTIMAL ROAD ACCESS FOR UWI ST AUGUSTINE SOUTH GATE
}

\author{
Rae J. Furlonge ${ }^{1^{*}}$ \\ ${ }^{1}$ Managing Director/Principal, LF Systems Ltd Consulting, Trinidad \\ ${ }^{1}$ Email: info@ccost.org*(Corresponding author)
}

\begin{abstract}
The primary access to the University of the West Indies, St Augustine Campus is located directly off the Churchill-Roosevelt Highway (CRH), an eastwest four-lane divided urban arterial road. This access is known as the South Gate and is set back 180 metres from the CRH but is made difficult by the crossing eastwest Watt Street, a collector road that services primarily pass-by traffic between the residential, commercial and school activities and the CRH. The high level of pass-by traffic comprises trips entering the area/intersection on the way from an external origin to an external destination, and includes through-traffic, as well as drop-off and pick-up of passengers. The morning and afternoon peak periods are particularly congested with the combined north-south UWI motorists and the eastwest Watt Street traffic, including the associated turning flows. The situation is exacerbated by the apparent limited land space availability, such as (1) the extremely close proximity of the UWI perimeter road to Watt Street, (2) some of the Engineering Faculty buildings constructed very near the existing UWI perimeter road, and (3) the layout configuration of the current road entry and exit as well as the associated green space, all complicate any approach to readily suggest the provision of a grand campus access and frontage. As the country's premier university in an urban environment, it is important that the campus emphasises its presence and visibility. In other words, the entire area should be reconfigured into a Campus Precinct. The constraints identified above have been taken into account in the assessment using SIDRA intersection traffic analysis software, and the resultant access tested with AIMSUN traffic simulation software.
\end{abstract}

Keywords: Double-lane roundabout, Intersection traffic analysis, and Traffic simulation modelling.

https://doi.org/10.47412/LJVJ9583

\section{Introduction}

Access management provides access to land development while simultaneously preserving the flow of traffic on the surrounding road network in terms of safety, capacity, and speed [1, p. 1]. Access management benefits the transportation system by preserving capacity, maintaining mobility, and improving safety.

The transportation network and traffic around universities are very complex transportation systems on account of the high vehicle density and concentration of pedestrian movement. Planning for access management for large trip generators like colleges and universities require to a great degree extensive research on the dynamic interaction between transportation and land use. Road safety 
and traffic flow issues associated with campus road networks become challenging with increased development and changes in land use around the periphery of these institutions. Effective planning can prevent and minimize the cost of corrective development since measures to mitigate the effect of these issues are often infeasible and or excessively expensive post-construction. The roadway network and the flow of traffic surrounding The University of the West Indies (UWI) are affected by its location relative to three major arterials. UWI, St. Augustine sits between the Churchill Roosevelt Highway ( $\mathrm{CRH})$ to the south and both the Eastern Main Road and Priority Bus Route to the north. Figure 1 shows UWI South Access Existing Layout Plan.

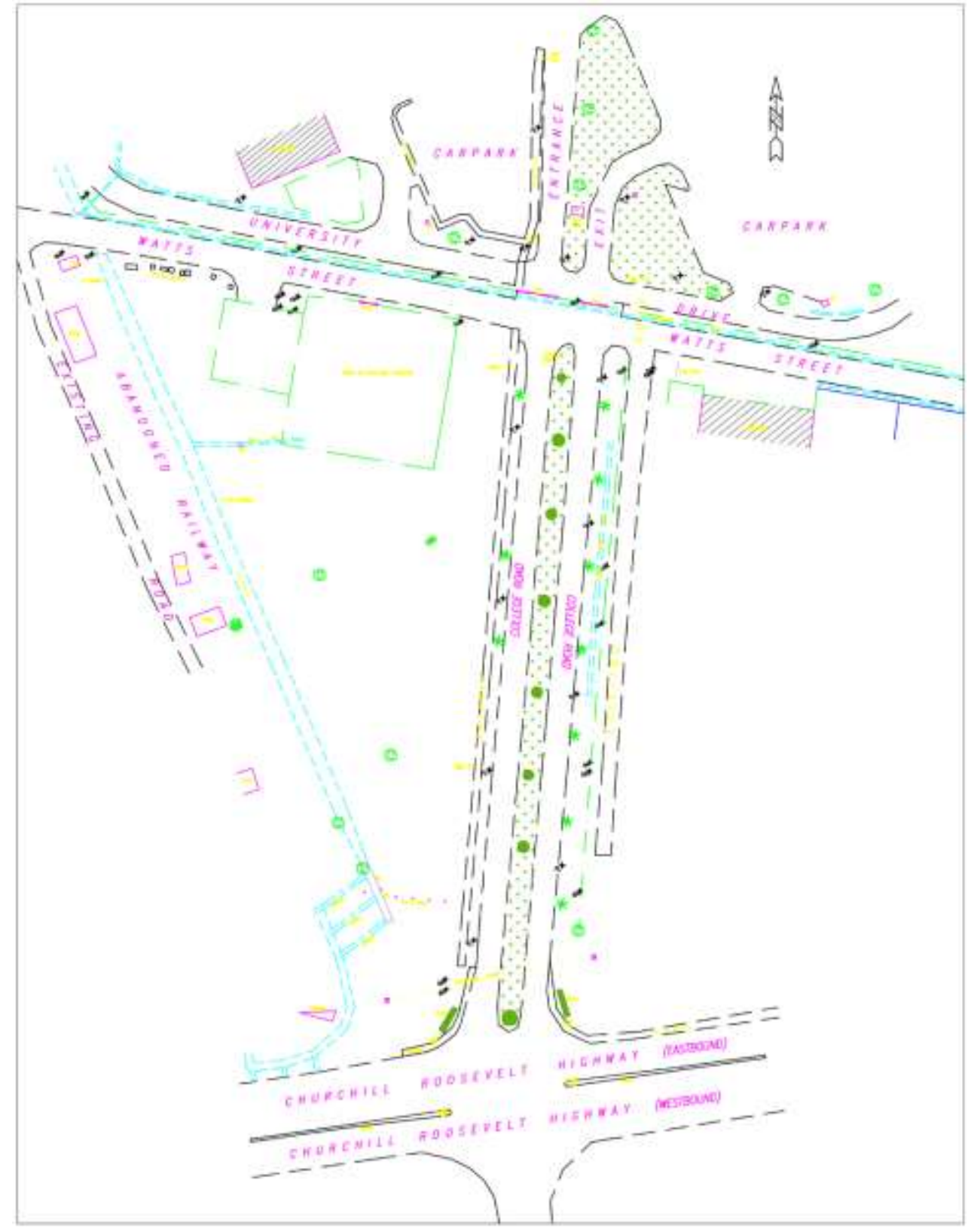

Figure 4: UWI South Access Existing Layout Plan. 
Access design should permit the safe and efficient processing of pedestrians, cars, trucks, and buses from public roadways onto access driveways and into parking areas. This involves establishing the length and taper of auxiliary turning lanes, driveway turning radii, width and storage, and the appropriate traffic controls [ibid., p. 98].

The Transportation Planning Handbook stated that access to the university campuses from the city's major arterials should be direct and should carry traffic to the intended campus entrances. It also points out that traffic not destined for the campus should be accommodated on arterial streets outside the campus boundaries [2, p. 450].

This paper seeks to seeks to improve the overall traffic flow at the primary access to/from the university at its intersection with College Road and Watts Street, St. Augustine.

\section{Background}

In 2004, UWI proposed to plan and design enhanced gateways for the northern and southern entrances to the St Augustine Campus. The aim of the traffic engineering study was to identify solutions to alleviate the traffic problems at the existing north and south gates. [3]. Among the conclusions made, the following are relevant to this paper:

(a) As a university in an urban environment it is important that the campus emphasises its presence and visibility as a campus precinct. Consequently, there should be intersection priority control change such that College Road should be the major road at intersection with Watts Street. This was accepted by UWI and presented to the Ministry of Works and Transport, Highways Division and Traffic Management Branch, but it was rejected, as they did not want to change the intersection priority.

(b) The Security Guard Booth is located about 20 metres north of the gate. It was proposed that the Security Guard Booth be re-located to a further 40 metres north of the gate in order to provide a longer throat. It is not known why this was not implemented.

(c) It was proposed that the left lane of the south approach at UWI South Gate should be used for both straight-through and left-turn, and the right lane be used of straight-through and right-turn. This was implemented.

(d) It was proposed that the left lane of the north approach at UWI South Gate should be used for both straight-through and left-turn, and the right lane be used of straight-through and right-turn. This was implemented.

UWI South Gate is currently located 180 metres north of the CRH at the intersection of Watts Street and College Road. College Road is a four-lane divided carriageway, with each two-lane carriageway about six metres wide between CRH and Watts Street, and about five metres wide on the northern side of the gate. Watts Street is about six metres wide and functions primarily as both a collector and local road. Watts Street is the major road at its intersection with College Road. The intersection of the CRH and College Road is signalized.

The campus is located in the East-West Corridor of the Greater Port-of-Spain Capital Region between the towns of Curepe and Tunapuna, and so is considered to be in an urban environment. 
The following principles should govern transportation planning for roadway systems and traffic circulation in an urban campus environment [4, p. 569-571]:

- Through-traffic should be directed away from the core area utilising alternative routes;

- Complex intersections should be avoided; and,

- Streets and land development should be designed to complement each other, that is, the local street pattern should not cut up the campus land areas into small parcels to frustrate sound development.

\section{Traffic Analysis}

Level of Service (LOS), in general, is a qualitative measure describing operational conditions within a traffic stream. LOS is described in terms of such factors as speed and travel time, freedom to manoeuvre, traffic interruptions, comfort and convenience, and safety. LOS at an intersection is determined in terms of control delay [5, p. 19-2]. Control delay is the portion of the total delay attributed to each lane on a given approach at an intersection [6]. Control delay can be categorized into deceleration delay, stopped delay and acceleration delay. Stopped delay is the delay incurred when a vehicle is fully immobilized, while the delay incurred by a decelerating or accelerating vehicle is categorized as deceleration and acceleration delay, respectively. The LOS per control delay definition is given below, in Table 1.

Table 1: Control Delay Definition of Level of Service

\begin{tabular}{|c|c|c|}
\hline LOS & $\begin{array}{c}\text { Control Delay (seconds per } \\
\text { vehicle) }\end{array}$ \\
\hline A & $0-10$ & \\
\hline B & $>10-15$ & \\
\hline C & $>15-25$ & \\
\hline D & $>25-35$ & \\
\hline E & $>35-50$ & \\
\hline F & $>50$ \\
\hline
\end{tabular}

For most urban areas, a LOS " $\mathrm{D}$ " is acceptable and LOS "C" $\mathrm{C}$ " is the standard in most in most rural areas. [7]

Twenty-four-hour video traffic data was collected for the intersection from Wednesday November 6 to 8, 2019. The highest total traffic approach volumes for morning and afternoon hours were considered the AM and PM peak hours, respectively. The AM total traffic approach volumes are higher than the PM.

Performance of the intersection was examined using SIDRA INTERSECTION version 8 traffic analysis software, as well as with AIMSUN version 8 transportation planning and microsimulation software.

SIDRA INTERSECTION software is an aid for design and evaluation of individual intersections and networks of intersections. It can be used to analyse all types of intersections including, major- 
minor stop sign control and roundabouts. It allows modelling of separate Movement Classes (Light Vehicles, Heavy Vehicles, Buses, etc.) with different vehicle characteristics. These movements can be allocated to different lanes, lane segments. It is an advanced micro-analytical traffic evaluation tool that employs lane-by-lane and vehicle path models coupled with an iterative approximation method to provide estimates of capacity and performance statistics (delay, queue length, stop rate, etc). SIDRA INTERSECTION provides facilities to calibrate its traffic models for local conditions. It provides software setups with appropriate default systems for different countries, allows the users to prepare customised software setups, provides a sensitivity analysis facility to allow testing of the effect of variations in values of various key parameters, and describes various calibration techniques. [8]

AIMSUN micro-simulator follows a microscopic simulation approach. This means that the behaviour of each vehicle in the network is continuously modelled throughout the simulation time period while it travels through the traffic network, according to several vehicle behaviour models (e.g., car following, lane changing). The system provides highly detailed modelling of the traffic network, it distinguishes between different types of vehicles and drivers, it enables a wide range of network geometries to be dealt with, and it can also model incidents, conflicting manoeuvres, etc. Most traffic equipment present in a real traffic network is also modelled in the Microsimulator: traffic lights, traffic detectors, Variable Message Signs, ramp metering devices, etc. The input data required by Aimsun dynamic simulators is a simulation scenario, and a set of simulation parameters that define the experiment. The scenario is composed of four types of data: network description, traffic control plans, traffic demand data and public transport plans. The simulation parameters are fixed values that describe the experiment (simulation time, warm-up period, statistics intervals, etc) and some variable parameters used to calibrate the models (reaction times, lane changing zones, etc). The outputs provided by Aimsun dynamic simulators are a continuous animated graphical representation of the traffic network performance, both in $2 \mathrm{D}$ and 3D, statistical output data (flow, speed, journey times, delays, stops), and data gathered by the simulated detectors (counts, occupancy, speed). [9]

\subsection{Current Intersection}

Figure 2 shows the Lane LOS for the current College Road/Watts Street intersection during the existing AM peak hour. The LOS for both lanes of the south approach (College Road) are unacceptable (LOS F), and the LOS for the right lane of the north approach is also unacceptable. The Lane LOS for the current College Road/Watts Street intersection during the existing PM peak hour is also unacceptable, as the LOS for the right lane of the south approach was unacceptable. 


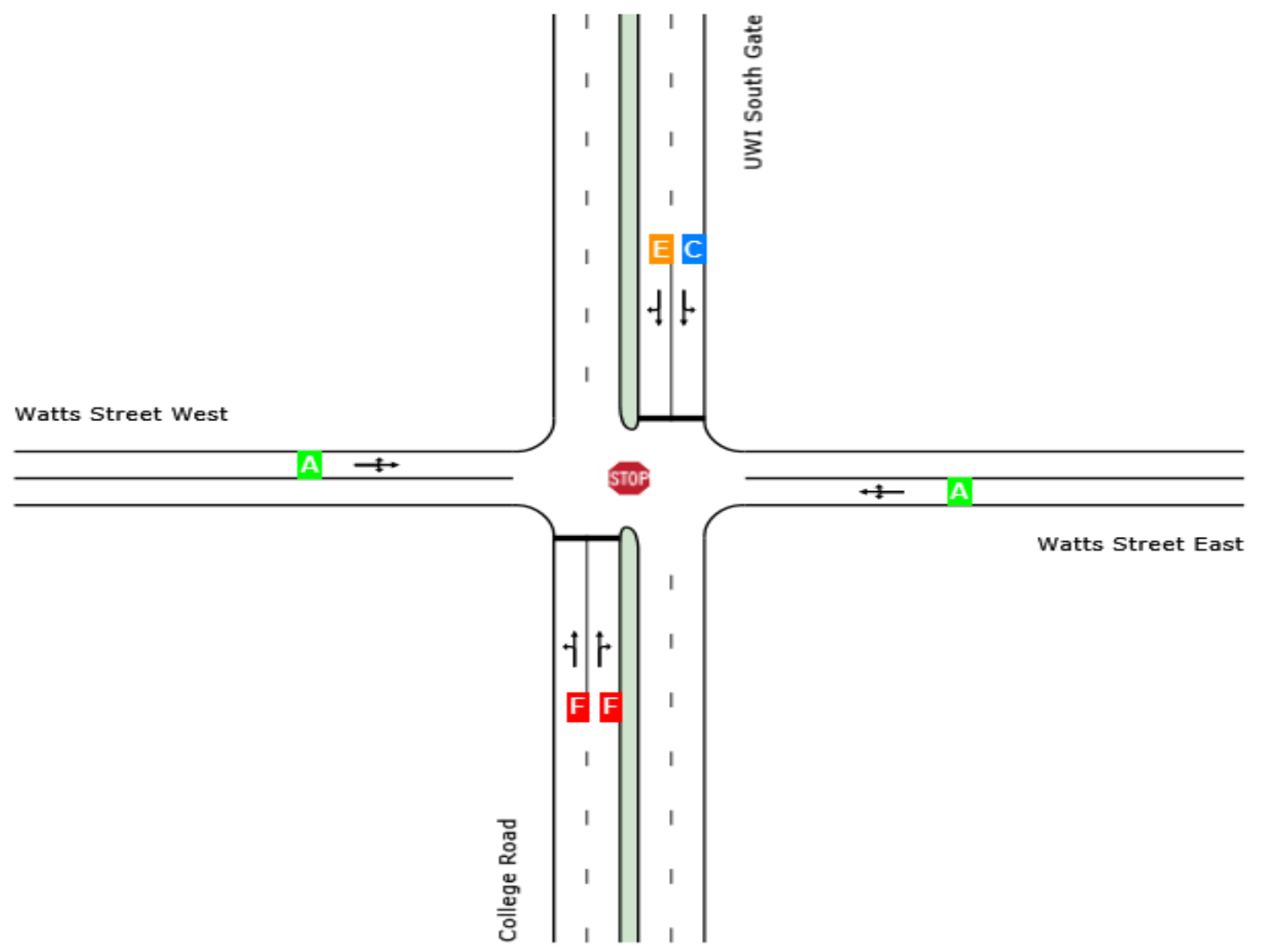

Figure 2: Lane Level of Service_C College Road/Watts Street - Existing AM Peak Hour

\subsection{Proposed Roundabout Intersection}

A double-lane roundabout has been proposed to replace the existing College Road/Watts Street major-minor stop intersection. It includes a smaller single-lane roundabout within the campus, connecting the existing eastern and western perimeter roads in a rearranged manner, in order to (a) facilitate access to the other areas around the campus, and (b) process visitors both welcome and unwelcome to the campus.

There appears to be limited land space availability for improvements to the existing intersection because of the following: (a) The extremely close proximity of the UWI perimeter road to Watt Street; (b) Some of the Engineering Faculty buildings constructed very near the existing UWI perimeter road; and, (c) The layout configuration of the current road entry and exit as well as the associated green space. These all would complicate any approach to readily suggest the provision of a grand campus access and frontage. Nevertheless, the proposed roundabout was laid out to overcome all these challenges.

The existing intersection has a north-south local road on the eastern side of College Road. This local road connects, and the proposed roundabout would cause this connection to be cut off. Its new access would be approximately midway on the southbound carriageway of College Road. 
Table 2 gives the basic parameters of the proposed roundabout. Entry Speed is the speed a vehicle is travelling at as it crosses the yield line. Entry Radius is the minimum radius of curvature of the outside curb at the entry. Inscribed Circle Diameter is the diameter of the largest circle that can be inscribed within the outer edges of the circulatory roadway. Circulating Roadway Width is the width between the outer edge of the circulating roadway and the central island, not including the width of any apron, where the apron is the mountable portion of the central island adjacent to the circulatory roadway. Entry Width is the width of the entry where it meets the inscribed circle, measured perpendicularly from the right edge of the entry to the intersection point of the left edge line and the inscribed circle. Entry Angle is a geometric proxy for the conflict angle between entering and circulating streams and is determined through a geometric construct. [10].

Table 2: Proposed Roundabout Basic Parameters

\begin{tabular}{|l|c|c|c|c|c|c|c|c|c|}
\hline $\begin{array}{c}\text { Road Approach } \\
\text { Name }\end{array}$ & $\begin{array}{c}\text { Central } \\
\text { Island } \\
\text { Dia (m) }\end{array}$ & $\begin{array}{c}\text { Circulating } \\
\text { Roadway } \\
\text { Width (m) }\end{array}$ & $\begin{array}{c}\text { Inscribed } \\
\text { Circle } \\
\text { Dia (m) }\end{array}$ & $\begin{array}{c}\text { Entry } \\
\text { Radius } \\
(\mathbf{m})\end{array}$ & $\begin{array}{c}\text { Entry } \\
\text { Angle } \\
\left({ }^{\circ}\right)\end{array}$ & $\begin{array}{c}\text { Circulating } \\
\text { Lanes (No.) }\end{array}$ & $\begin{array}{c}\text { Entry } \\
\text { Lanes } \\
(\text { No. })\end{array}$ & $\begin{array}{c}\text { Av. Entry } \\
\text { Lane } \\
\text { Width } \\
(\mathbf{m})\end{array}$ & $\begin{array}{c}\text { Approach } \\
\text { Dist (m) }\end{array}$ \\
\hline College Road & $\mathrm{m}$ & $\mathrm{m}$ & $\mathrm{m}$ & $\mathrm{m}$ & & No. & No. & $\mathrm{m}$ & $\mathrm{m}$ \\
\hline Watts Street East & 26 & 10 & 46 & 20 & 26 & 2 & 2 & 3.65 & 168 \\
\hline UWI South Gate Rd & 26 & 10 & 46 & 20 & 26 & 1 & 2 & 3.65 & 192 \\
\hline Watts Street West & 26 & 10 & 46 & 20 & 26 & 2 & 1 & 3.65 & 56 \\
\hline
\end{tabular}

Figure 3 shows the Lane LOS for the proposed College Road/Watts Street roundabout intersection during the existing AM peak hour. The LOS is good. The Lane LOS for the proposed College Road/Watts Street roundabout intersection during the existing PM peak hour is also good.

This consultant has assumed an annual non-site traffic growth rate of two (2) percent. Thus, in ten years, the annual vehicular growth of 2 percent results in a factor of $(1+0.02)^{10}$ or 1.2 to be multiplied to the directional vehicle volumes. It is assumed that the directional split would remain the same. Analysis of the projected data to year 2029 for the roundabout intersection showed that the LOS is still good during both AM and PM peak hours. 


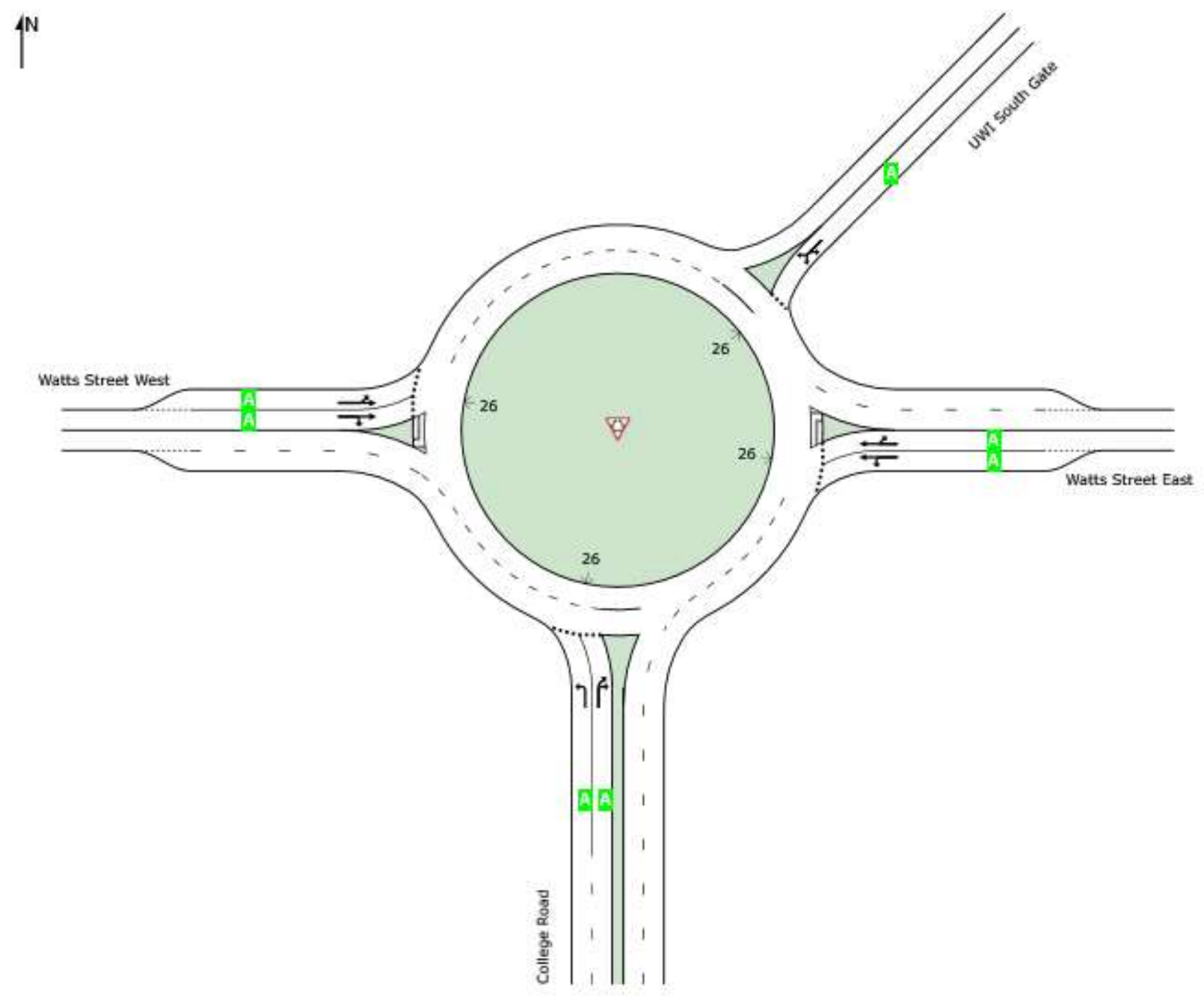

Figure 3: Lane Level of Service — College Road/Watts Street - Proposed Roundabout during AM Peak Hour

\subsection{Traffic Simulation}

Figure 4 gives the simulated volume/capacity (VC) ratio for the proposed College Road/Watts Street roundabout intersection during the existing AM peak hour. VC ratio is the ratio of the number of vehicles traversing a point or uniform segment of a lane or roadway during a specified time period (in this case, per hour) to the maximum sustainable number of vehicles which reasonably can be expected to traverse the point or uniform segment of a lane or roadway during a specified time period under prevailing roadway, geometric, traffic, environmental, and control conditions (expressed as vehicles per hour). The VC ratio is good. The simulated volume/capacity (VC) ratio for the proposed College Road/Watts Street roundabout intersection during the existing PM peak hour is also good. 


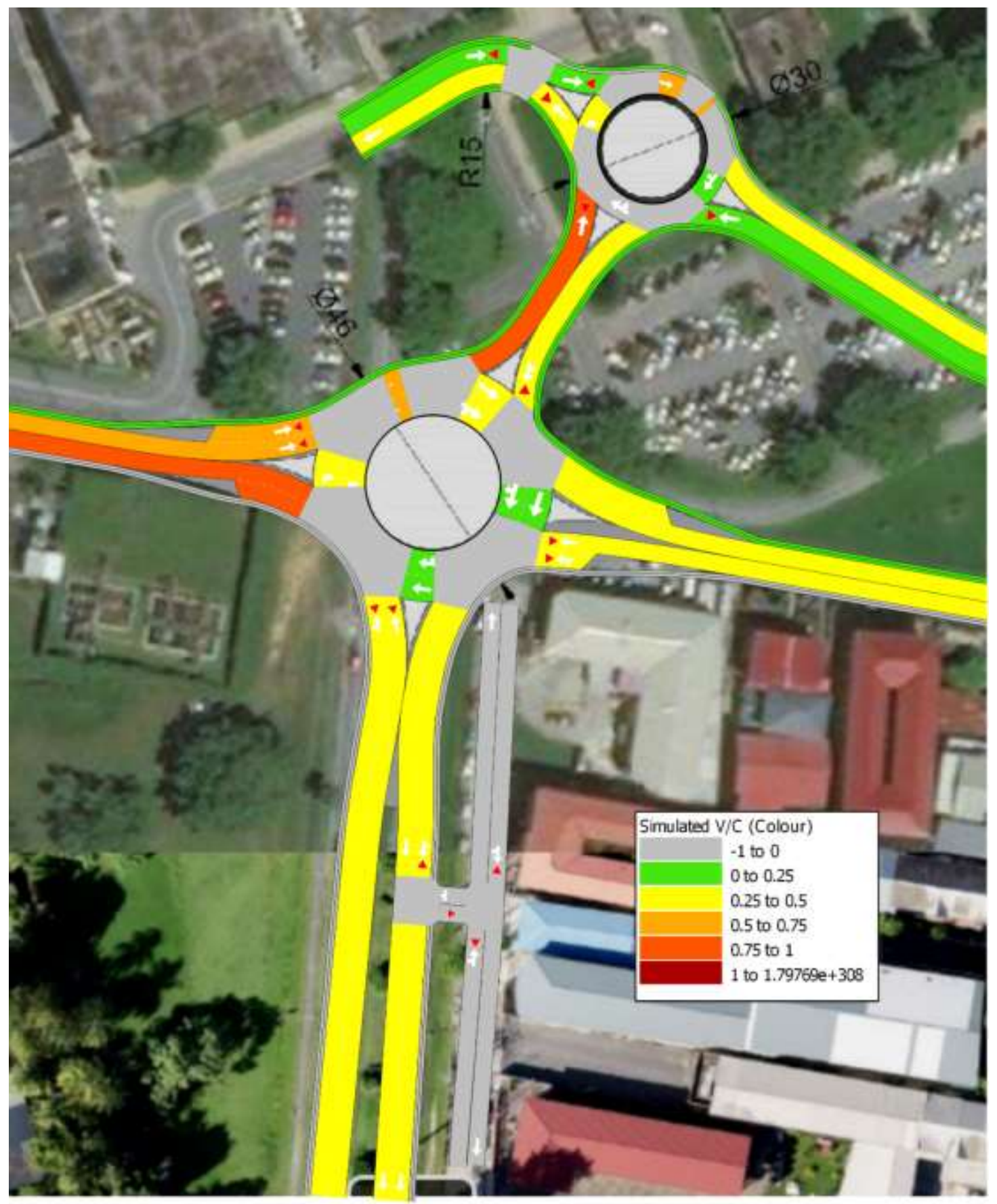

Figure 4: Simulated Volume/Capacity Ratio - College Road/Watts Street - Proposed Roundabout during AM Peak Hour 


\section{Conclusion}

The following may be concluded from this study:

1. The authorities appear hesitant to reconfigure the intersection of College Road and Watts Street such that College Road would be the major road, in order to establish this critical southern access as part of a university campus precinct, as they have refused to act on the earlier recommendations.

2. A double-lane roundabout has been proposed to replace the existing College Road/Watts Street major-minor stop intersection, and more importantly, to alleviate the tremendously frustrating current weekday traffic congestion during AM and PM periods. It includes a smaller single-lane roundabout within the campus, connecting the existing eastern and western perimeter roads in a rearranged manner, in order to (a) facilitate access to the other areas around the campus, and (b) process visitors both welcome and unwelcome to the campus. The traffic operations of this proposal would remove the need for reconfiguration of the current major-minor stop requirement.

3. Traffic analysis of the proposed roundabout showed the Level of Service to be good using existing data, as well as projected data for at least the next ten years. In addition, traffic simulation during these periods also displayed very satisfactory volume-capacity ratios for all lane approaches.

4. There appears to be limited land space availability for improvements to the existing intersection because of the following: (a) The extremely close proximity of the UWI perimeter road to Watt Street; (b) Some of the Engineering Faculty buildings constructed very near the existing UWI perimeter road; and, (c) The layout configuration of the current road entry and exit as well as the associated green space. These all would complicate any approach to readily suggest the provision of a grand campus access and frontage. Nevertheless, the proposed roundabout was laid out to overcome all these challenges.

5. The existing intersection has a north-south local road on the eastern side of College Road. This local road connects, and the proposed roundabout would cause this connection to be cut off. Its new access would be approximately midway on the southbound carriageway of College Road.

\section{References}

[1.] F. J. Koepke, H. S. Levinson. 1992. Access Management Guidelines for Activity Centers. NCHRP Report 348, Transportation Research Board, National Research Council, Washington, DC.

[2] M. D. Meyer. 2009. Transportation Planning Handbook, 3rd Edition, Institute of Transportation Engineers (ITE), Washington, DC.

[3] All-Inclusive Project Development Services Limited (APDSL). 2005. Enhanced Gateways for the Northern and Southern Entrances-Traffic Engineering Study: Final Report, The University of the West Indies, St. Augustine Campus, Projects Office.

[4] Institute of Transportation Engineers. 1999. Transportation Planning Handbook, Second Edition, J. D. Edwards, Jr., (ed.), ITE, Washington, D.C.

[5] Transportation Research Board (TRB). 2010. Highway Capacity Manual HCM2010, Volume 3: Interrupted Flow, Washington, D.C. 
[6] Transportation Research Board (TRB). 2000. Highway Capacity Manual 2000, National Research Council, Washington D.C.

[7] Highway Capacity Manual. 2010. Volume 3: Interrupted Flow. Chapter 19-Two-Way StpControlled Intersections, page 19-2.

[8] Akcelik and Associates Pty Ltd. 2019. SIDRA INTERSECTION 8 Powerful Lane-Based Network Analysis. Version 8.0.7.7948. Greythorne, Victoria, Australia. www.sidrasolutions.com. [9] TSS-Transport Simulation Systems, 2013, Aimsun 8 Dynamic Simulators Users' Manual, October.

[10] NCHRP REPORT 672. 2010. Roundabouts-An Informational Guide, Second Edition, Transportation Research Board, Washington, DC, USA 